\title{
VERIFICATION OF THE WATER TRANSPORT PARAMETER - MOISTURE STORAGE FUNCTION OF AUTOCLAVED AERATED CONCRETE - APPROXIMATELY CALCULATED FROM A SMALL SET OF MEASURED CHARACTERISTIC VALUES
}

The aim of the paper is to determine the moisture transport parameters for selected type of autoclaved aerated concrete using fly ash order to carry out the numerical analysis of the hygrothermal performance of selected building structures in real conditions. The moisture storage function (sorption, suction) and the liquid water transport coefficient are taken into consideration. Obtaining knowledge of these parameters involves a series of laboratory measurements and tests. Applying those parameters into modern calculation methods (WUFI) we will be able to analyse annual hygrothermal performance of porous concrete wall constructions in climatic conditions of Central Europe. This article aims to test use of a simplified approximating method to establish the moisture storage function for a chosen building material. Influences of the method on accuracy of the simulated calculation will also be analysed.

Key words: moisture storage function, liquid transport coefficient, simulation tools

\section{Introduction}

In order to predict hygrothermal performance of building components and elements, the computer simulation (HAM software) [8], requires moisture storage and transport properties data. The high quality of the material properties data, especially Moisture storage function and Liquid transport coefficient, are the basis for the modelling [10]. Implementation of moisture storage function (sorption, suction) and liquid water transport coefficient allows monitoring not only the water transport due to water vapour diffusion (Glaser model) but also receiving water and its redistribution due to capillarity. Obtaining knowledge of these properties involves a series of laboratory measurements and tests. Thus, the current simulation tools have only few material data files that cannot satisfy the increasing simulation requirements. Application of such "similar" material data - as proxy for the inexistent ones - within the simulation process is debatable. When the exactly measured data are not available and we want to avoid the data for similar material, we have an option to use approximating calculation from characteristic measured point. We can input specific materials, described by the material data, into the simulation tool as:

- a similar material taken from the database of the simulation programme,

- approximately calculated from characteristic measured point,

- precisely measured values for a concrete material.
The aim of this analysis is a comparison of given alternatives and their impact on results. We also monitor water content (water profiles and calculated course of the water content) inside a building's envelope. Construction material characteristic for the unified construction of panel housing in Slovakia between 1970-1972 were selected for the purposes of the present analysis. The result (measured and approximately calculated) is compared with a similar type of an autoclaved aerated concrete 600 (old style) from the simulation tool WUFI 4 [9].

\section{Input processes}

\subsection{Selected building material used for analysing}

This type of autoclaved aerated concrete listed below has been selected to be studied in the [8]. It was frequently used in constructions of residential houses, as well as non-residential buildings and production halls.

Autoclaved aerated concrete $P B$ is a light concrete with silica filling - ash and gas silicate or more frequently gas concrete; mixed with foaming additive (aluminium powder) macropores are created (Fig. 1).

\footnotetext{
* Pavol Durica ${ }^{1}$, Marian Vertal ${ }^{2}$

${ }^{1}$ Faculty of Civil Engineering, University of Zilina, Slovakia, E-mail: pavol.durica@fstav.uniza.sk

${ }^{2}$ Institute of Architectural Engineering, Technical University of Kosice, Slovakia
} 

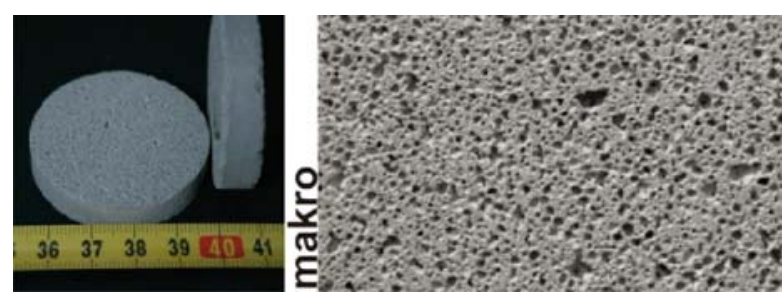

Fig. 1 Porous concrete PB specimens ready for measuring

It was used in single-layer external cladding of panel constructions systems (T 06 B, T 08 B - Fig. 2) of flat blocks, skeletal structural systems (e.g. MS 66, MS RP, S 1.2, BAUMS) in civic amenities (schools, shopping centres, etc.) and in type constructions of single- and double-layer flat roofs of the presented constructions.
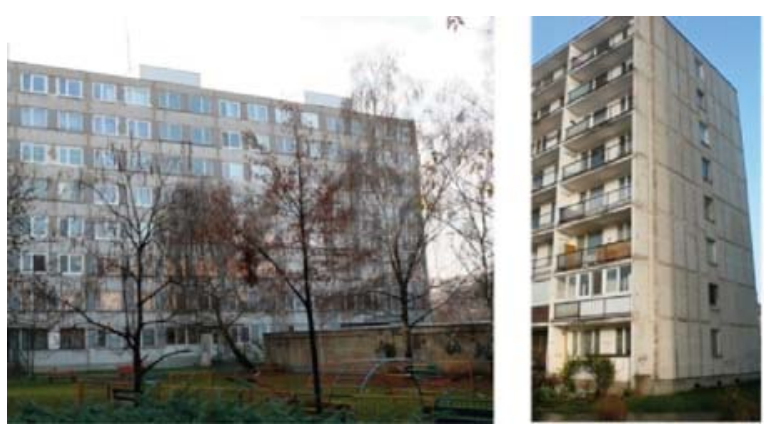

Fig. 2 Panel block of flats structural system T08B, row and solo house Kosice

Its use grew significantly in large-scale development between 1970 and 1992 and it is still ranked among the most utilized building materials, however, its properties have been refined. $240 \mathrm{~mm}$ thick samples for the research purposes ( 6 core drills of $45 \mathrm{~mm}$ in diameter) were obtained from the walls of the panel structure T 08 B KE in Lunik 2 housing residential area, Kosice. The panels were manufactured in the former Panel Works Plant in Vranov nad Toplou (Hencovce), Slovakia, using Polish technology Unipol in 1964. The samples were taken in November 2006.

\subsection{Analyzed building's envelope}

A type of autoclaved aerated concrete compared to autoclaved aerated concrete 600 (old style) was used as a load bearing material. In simulation processes these alternatives were calculated:

- autoclaved aerated concrete $600 \mathrm{AC} 600$,

- aerated concrete PB (app. calculated) AC PB,

- aerated concrete PB (exactly measured) AC PB.

Cement lime plaster was used as external finish and gypsum plaster was used as internal finish (Fig. 3).

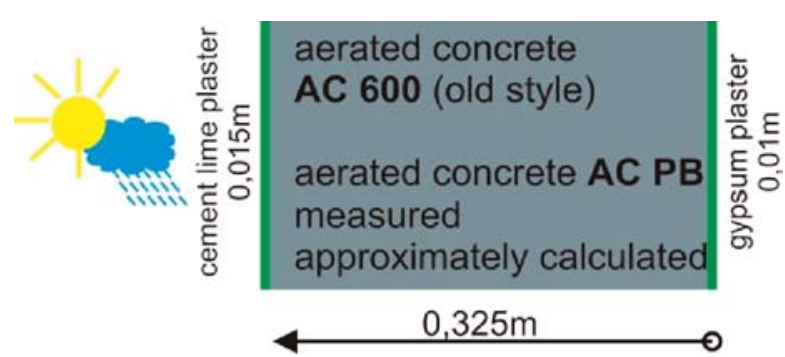

Fig. 3 Scheme of the analyzed building's envelope

\subsection{Basic material characteristics - material data}

The overview of basic material parameters is given in Table 1:

Basic material characteristics of

Tab. 1 used envelopes

\begin{tabular}{|c|c|c|c|c|}
\hline & AC 600 & AC PB & CL ex. & Gint. \\
\hline$\rho\left[\mathrm{kg} / \mathrm{m}^{3}\right]$ & 600 & 627 & 1900 & 850 \\
\hline$p[\%]$ & 72 & 70 & 24 & 65 \\
\hline$c[\mathrm{~J} /(\mathrm{kg} \cdot \mathrm{K})]$ & 850 & 850 & 850 & 850 \\
\hline$\mu[-]$ & 8 & 8 & 19 & 8,3 \\
\hline$\lambda_{d r y}[\mathrm{~W} /(\mathrm{m} \cdot \mathrm{K})]$ & 0.14 & 0.14 & 0.8 & 0.2 \\
\hline$w_{f}\left[\mathrm{~kg} / \mathrm{m}^{3}\right]$ & 340 & 528 & 210 & 400 \\
\hline$A\left[\mathrm{~kg} /\left(\mathrm{m}^{2} \cdot \mathrm{s}^{0,5}\right)\right]$ & 0.083 & 0.057 & 0.03 & 0.287 \\
\hline \multicolumn{5}{|c|}{$\mathrm{AC}-$ aerated concrete, CL - cement lime plaster, } \\
G - gypsum plaster \\
\hline
\end{tabular}

where $\rho$ is bulk density $\left[\mathrm{kg} / \mathrm{m}^{3}\right], p$ is porosity [\%], $c$ is specific heat capacity $[\mathrm{J} /(\mathrm{kg} . \mathrm{K})], \mu$ is water vapour diffusion resistance factor $[-], \lambda_{d r y}$ is thermal conductivity in dry state $[\mathrm{W} /(\mathrm{m} . \mathrm{K})], w_{f}$ is free water saturation $\left[\mathrm{kg} / \mathrm{m}^{3}\right]$ and $\mathrm{A}$ is water absorption coefficient $\left[\mathrm{kg} /\left(\mathrm{m}^{2} \cdot \mathrm{s}^{0,5}\right)\right]$.

\subsection{Water transport parameters - material data}

The main water transport parameters in buildings materials are:

- moisture storage function (sorption and suction curve),

- liquid transport coefficients,

- water vapour diffusion resistance factor.

\subsubsection{The measured points of moisture storage function} in low moisture range - Sorption curve

The sorption curve covers the sorption moisture region, i.e. hygroscopic range up to $97 \%$ (95) of relative air humidity (Fig. 4). 
Measuring procedure of the sorption curve was carried out by the method of parallel exposure [8].

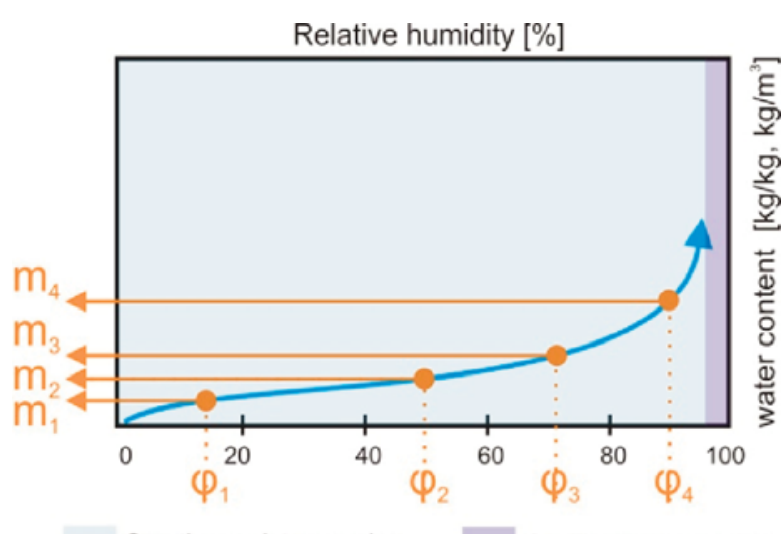

Sorption moisture region

Capillary water region

Fig. 4 Moisture storage function (sorption curve) of a porous material

\subsubsection{The measured points of moisture storage function} in high moisture range - Suction curve

Several measuring devices and techniques based on various physical principles can be used for measuring suction curve defining water accumulation in capillary water region Fig. 5. The method in which the determining measuring medium is water comprised in the sample was selected for the purposes of measuring the analysed materials. This method is referred to [2] as sufficiently precise, particularly suitable for the evaluation of the building materials whose porous systems have been exposed to external conditions (weather, pollution, impact of salts etc.). Measuring was conducted by means of pressure plate extractors produced by Soilmoisture Equipment Corp. [5, 6] - Figs. 6 and 7.

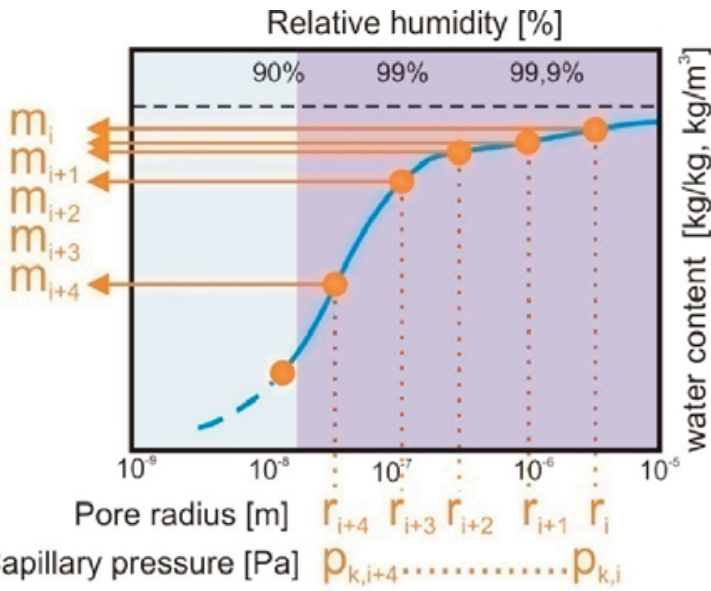

Sorption moisture region Capillary water regio Fig. 5 Moisture storage function (suction curve) of a porous material

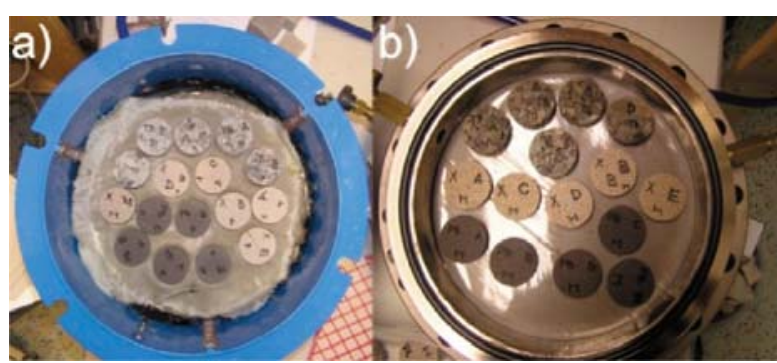

Fig. 6 a) pressure plate extractor PPE,

b) pressure membrane extractor PME before setting pressure level

The concept of measuring lies in observations and recording of water weight loss in the saturated sample corresponding to the pressure inducing the change (see Tab. 2 and 3). Fig. 9 shows schematic connection of pressure plate and membrane extractor.

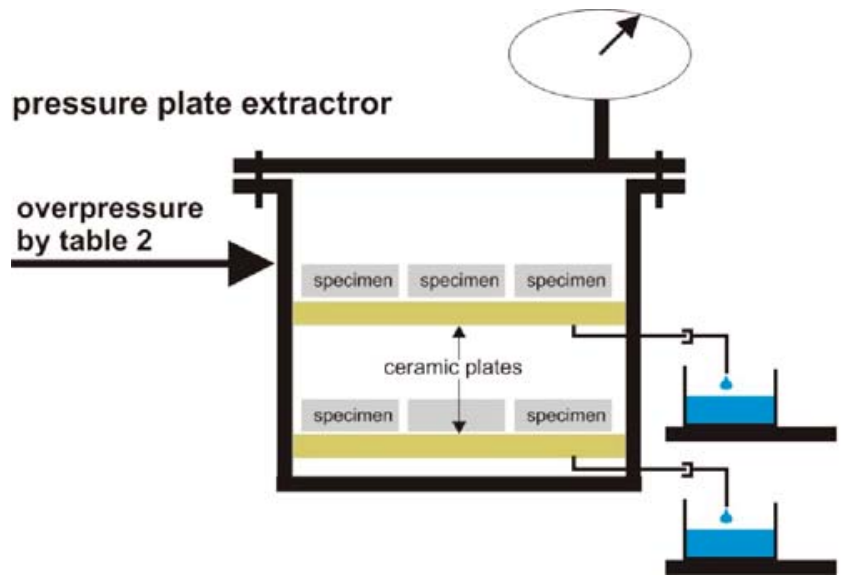

\section{pressure membrane extractror}

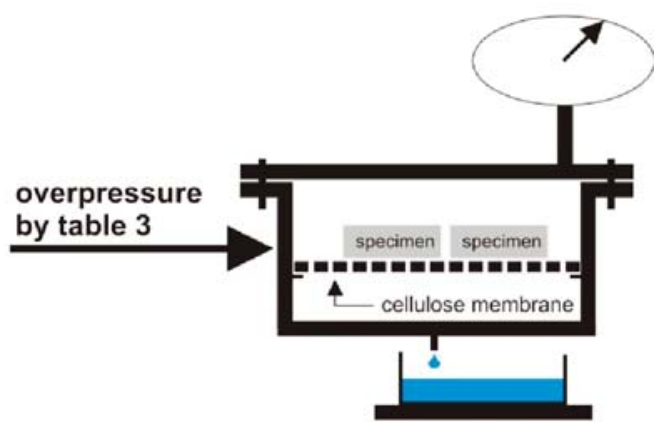

Fig. 7 Pressure plate (PPE) left and Pressure membrane (PME) extractor right 


\begin{tabular}{|l|c|c|c|c|c|c|c|c|}
\hline Apparatus & \multicolumn{9}{|c|}{ Pressure Plate Extractor } \\
\hline Pressure level (i) & 1 & 2 & 3 & 4 & 5 & 6 & 7 & 8 \\
\hline Pressure [Pa] & $10^{2}$ & $10^{2,5}$ & $10^{3}$ & $10^{3,5}$ & $10^{4}$ & $10^{4,5}$ & $10^{5}$ & $10^{5,5}$ \\
\hline Pressure [bar] & 0.001 & 0.00316 & 0.01 & 0.0316 & 0.1 & 0.316 & 1 & 3.16 \\
\hline
\end{tabular}

Suction pressure set points (PME)

\begin{tabular}{|l|c|c|c|}
\hline Apparatus & \multicolumn{3}{|c|}{ Pressure Membrane Extractor } \\
\hline Pressure level (i) & 9 & 10 & 11 \\
\hline Pressure [Pa] & $10^{6}$ & $10^{6,5}$ & $10^{7}$ \\
\hline Pressure [bar] & 10 & 31.6 & 100 \\
\hline
\end{tabular}

\subsubsection{Approximate calculation of moisture storage function in low and high moisture range}

The moisture storage function was approximately calculated by equation $1[1]$ :

$$
w\left(p_{k}\right)=\frac{w_{f}}{1+\left(\frac{\rho_{w} \cdot r_{p} \cdot T \cdot \ln \Phi}{p_{k 1}}\right)^{p k 2}}
$$

where

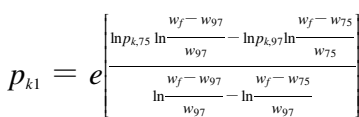

$$
\begin{aligned}
& p_{k 2}=\frac{\ln \frac{w_{f}-w_{75}}{w_{75}}}{\ln \frac{p_{k, 75}}{p_{k 1}}}=\frac{\ln \frac{w_{f}-w_{75}}{w_{75}}}{\ln p_{k, 75}-\ln p_{k 1}}= \\
& =\frac{\ln \frac{w_{f}-w_{97}}{w_{97}}}{\ln p_{k, 97}-\ln p_{k 1}}
\end{aligned}
$$

where $\rho_{w}$ is the water density $\left[\mathrm{kg} / \mathrm{m}^{3}\right], r_{p}=462 \mathrm{~J} /(\mathrm{kg} . \mathrm{K})$ is the gas constant of water vapour and $p_{k 1}, p_{k 2}$ are free parameters [-].

Moisture storage function for AC PB (measured and approximately calculated) [8] compared to AC 600 (old style) (WUFI 4) are shown in Fig. 8.

\subsubsection{Liquid transport coefficient}

Liquid transport coefficients were approximately calculated by equation (4) [3]:

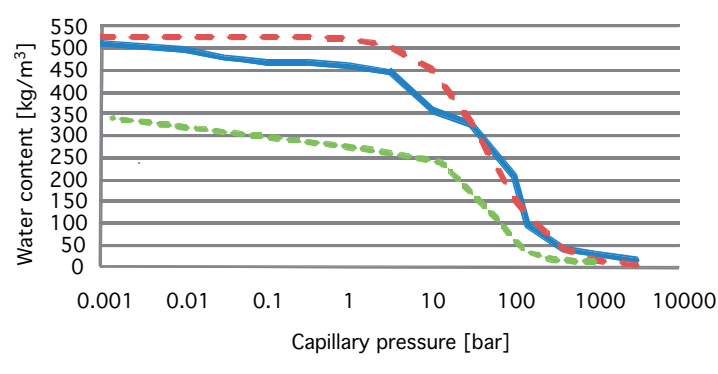

AC PB measured values $=$ AC PB approx. by equation (1)

$=-{ }_{-1}$ AC 600 old style (WUFl database)

Fig. 8 Moisture storage functions for AC 600 (WUFI 4) and $A C P B$ (measured and approximately calculated)

$$
\begin{aligned}
& w_{f} \frac{A^{2}}{\left(w_{f}-w_{80}\right)}=\frac{4\left(D_{w f}-D_{w 0}\right)}{K \pi \ln \left(\frac{D_{w f}}{D_{w 0}}\right)} \\
& \left.K=0,025 \cdot 10^{\left(-0,4 \cdot\left(\log \frac{D_{w f}}{D_{w 0}}\right)-3\right.}\right)+0,61
\end{aligned}
$$

where $D_{W}$ is liquid diffusivity $\left[\mathrm{m}^{2} / \mathrm{s}\right], D_{W 0}=2.10^{-10} \mathrm{~m}^{2} / \mathrm{s}$ is liquid diffusivity by reference water content, hygroscopic range - constant, $D_{w f}$ is liquid diffusivity by free saturation $\left[\mathrm{m}^{2} / \mathrm{s}\right]$.

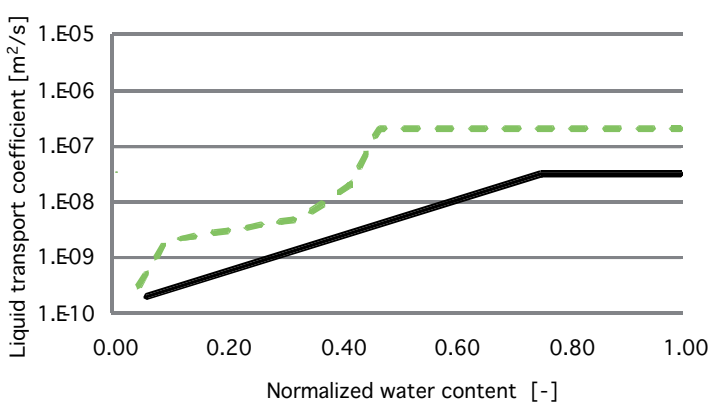

AC PB approx, by equation (4) _ _

Fig. 9 Liquid transport coefficients for AC 600 (WUFI 4) and $A C P B$ (approximately calculated)

Liquid transport coefficients for AC X and AC PB compared to AC 600 (old style) (WUFI 4) are shown in Fig. 9. 
Water transport parameters for

Table 4 alternatives of simulation

\begin{tabular}{|c|c|c|c|}
\hline & $\begin{array}{c}\text { AC 600 old } \\
\text { style similar } \\
\text { data }\end{array}$ & $\begin{array}{c}\text { AC PB approx. } \\
\text { calculated }\end{array}$ & $\begin{array}{c}\text { AC PB } \\
\text { measured }\end{array}$ \\
\hline $\begin{array}{c}\text { Moisture } \\
\text { storage function }\end{array}$ & database WUFI & $\begin{array}{c}\text { approximately } \\
\text { calc. by the eq. } \\
(1)\end{array}$ & measured \\
\hline $\begin{array}{c}\text { Liquid transport } \\
\text { coefficient }\end{array}$ & database WUFI & $\begin{array}{c}\text { approximately } \\
\text { calc. by the eq. } \\
(4)\end{array}$ & $\begin{array}{c}\text { approximately } \\
\text { calc. by the eq. } \\
(4)\end{array}$ \\
\hline $\begin{array}{c}\text { water vapour } \\
\text { diffusion } \\
\text { resistance factor }\end{array}$ & constant value & $\begin{array}{c}\text { constant value } \\
\text { measured }\end{array}$ & $\begin{array}{c}\text { constant value } \\
\text { measured }\end{array}$ \\
\hline
\end{tabular}

\section{Simulation}

\subsection{Initial and boundary conditions}

As boundary conditions in the exterior we used climatic data for Vien, Vien Hohe Varte (halfsynthetic long-year climate data set 1976-2005) (WUFI 4). On the interior side we had values given by EN 15 026, normal moisture load respectively. Initial conditions corresponded to values of interior temperature and relative humidity. The simulation was done for 3-years period (1. 10. $2011-1.10$. 2014).

\subsection{Mathematical model}

The analysis was realized by the simulation tool WUFI (WUFI 4),- a 1D analysis of heat and water transport as described by Kunzel. In Kunzel's model, moisture and heat balance equations are formulated as [4]:

$$
\begin{aligned}
& \frac{d w}{d \varphi} \frac{\partial \varphi}{\partial t}=\nabla \cdot\left(\left(D_{\phi} \nabla \varphi+\delta_{p} \nabla\left(\varphi \cdot p_{s a t}\right)\right)\right) \\
& \frac{d H}{d T} \frac{\partial T}{\partial t}=\nabla \cdot(\lambda \nabla T)+h_{v} \nabla \cdot\left(\delta_{p} \nabla\left(\varphi \cdot p_{s a t}\right)\right)
\end{aligned}
$$

where $d H / d T$ is the heat storage capacity of the moist building material $\left[\mathrm{J} /\left(\mathrm{m}^{3} \cdot \mathrm{K}\right)\right], \varphi$ the relative humidity [\%], $\delta$ the water vapour permeability $[\mathrm{kg} /(\mathrm{m} . \mathrm{s} . \mathrm{Pa})], p_{\text {sat }}$ the partial pressure of saturated water vapour in the air $[\mathrm{Pa}], h_{v}$, the latent heat of evaporation of water $[\mathrm{J} / \mathrm{kg}], \lambda$ the thermal conductivity $[\mathrm{W} /(\mathrm{m} . \mathrm{K})]$ and $T$ is the temperature $\left[{ }^{\circ} \mathrm{C}\right]$.

The liquid water transport coefficient is defined as:

$$
D_{\phi}(w)=D_{w}(w) \cdot \frac{d w}{d \varphi}
$$

\section{Output processes - results}

Fig. 10 shows water profiles for aerated concrete 600 (old style) from the WUFI database and aerated concrete AC PB (measured and approximately calculated see Tab. 4) at three moments (18. 04. 2012, 26. 4. 2014 and 1. 10. 2014).
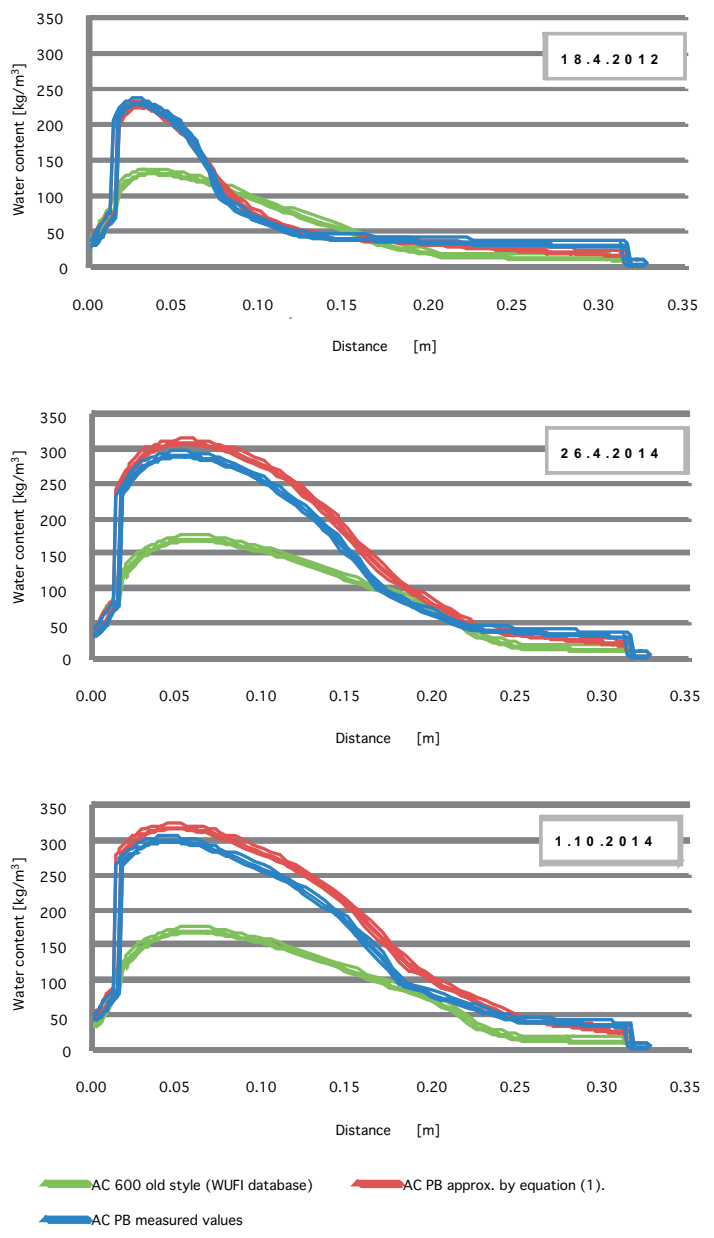

Fig. 10 Water profiles for $A C 600$ and $A C P B$ (measured and approximately calculated)

Fig. 11 shows courses of water content within the simulation interval (1. 10. 2011 - 1. 10. 2014). As the graphs in Figs. 10 and 11 shows the water content stored within the building construction differs. In the case of the selection of similar materials (in this case autoclaved aerated concrete 600 old style) water profiles as well as water courses differ significantly. The difference is up to $38 \%$. It is clear from this analysis that use of similar materials instead of concretely measured data can lead to significant mistakes in calculations. The water profiles, data from which are approximately 


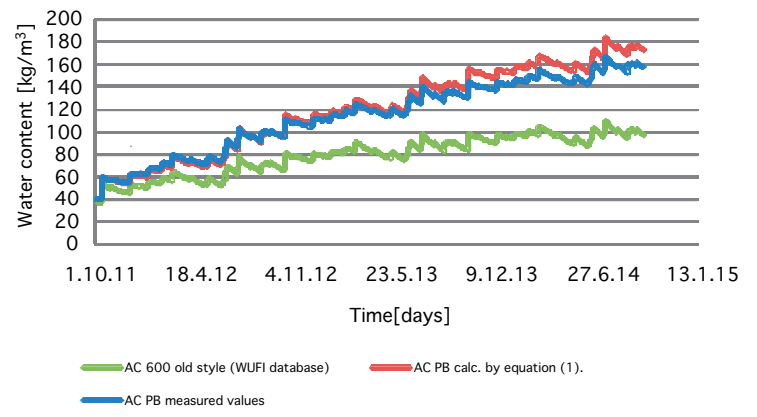

Fig. 11 Courses of water content for AC 600 and AC PB (measured and approximately calculated)

calculated (equation 1), copy the profiles calculated from exactly measured values. The difference is significantly low (under 10\%).

\section{Conclusion}

Constant improvement of simulation tools is a natural expression of developments of the human society. Today, moisture inside of building envelopes is evaluated according to approximate models of calculations. These are based on so-called Glaser's, normally stationary, principles. This simplified procedure is not capable of recognising real processes happening with a building material, or to evaluate its behaviour during the analysed period.
On the other hand, there exist modern, normally non-stationary and very precise simulation tools. As the present numerical analysis showed, sensitivity of these methods to quality of input data is very high. Where relevant input data exist, application of simulation models is very broad. They offer a broad range of outputs that allow analysis of little used building materials directly in their natural built-in climactic conditions. As argued also in references [1] and [7], approximating relations are based on measuring characteristic points that are sufficiently exact to be used in simulation tools (HAM software) in the area of Building physics.

Correctly calculated results can be also used as:

- analysis of influence of ETICS on hygrothermal performance in any analysed building,

- analysis of influence of new surface material layers (exterior and interior) on drying capability of a building,

- analysis of influence of immediate amount of water in a material on levels of its thermal conductivity, within the context of a nonstationary $\mathrm{U}$ value, and on the related transmission heat loss coefficient connected,

- analysis and optimisation of details of building constructions with a help of 2D hygrothermal analysis,

- analysis and prediction of creation of mould growth with using the WUFI Bio tool,

- exact calculations of low - energy houses [10], [11],

- analysis of influence of salts and contamination of the cavity system in a material on water transport,

- etc.

\section{References}

[1] KRUS, M.: Approximation der Feuchtespeicherfunktion aus einfach bestimmbaren Kennwerten Mitteilung 406, 2002.

[2] KRUS, M.: Feuchtetransport- und Speicherkoeffizienten porosermineralischer Baustoffe. Theoretische Grundlagen und neue Messtechniken, Ph.D. dissertation, Stuttgart, 1995.

[3] KRUS, M., HOLM, A., SCHMIDT, T.: Ermittlung der Kapillartransportkoeffizienten mineralischer Baustoffe aus dem w - Wert. Sonderdruck aus Bauinstandsetzen 4, Holzkirchen, 1998.

[4] KUNZEL, H.M.: Verfahren zur ein - und zweidimensionalen Berechnung des gekoppelten Warme- und Feuchtetransports in Bauteilen mit einfachen Kennwerten, Ph.D. dissertation, Stuttgart, 1994.

[5] SOILMOISTURE EQUIPEMENT CORP. OPERATING INSTRUCTIONS: - 5 bar Pressure plate extractor.

[6] SOILMOISTURE EQUIPEMENT CORP. OPERATING INSTRUCTIONS: - 100 bar Pressure membrane extractor.

[7] VERTAL, M., DURICA, P.: Bestimmung von feuchtetechnischen Material - parametern ausgewahlter Baumaterialien fur die rechnerische Bewertung von Baukonstruktionen unter den Bedingungen in der Slowakei, Berlin, 2009.

[8] VERTAL, M.: Analysis of Heat and Humidity Transport by External Walls (in Slovak), Ph.D. dissertation, Kosice, Slovakia, 2009.

[9] WUFI 4: Software for Calculating the Coupled Heat and Moisture Transfer in Building Components.

[10] KORJENIC, A., TEBLICK, L., BEDNAR, T.: Increasing the Indoor Humidity Levels in Buildings with Ventilation Systems: Simulation Aided Design in Case of Passive Houses, Building Simulation, Vol. 3, pp. 295-310, 2010.

[11] KAMENSKY, M, BAGONA, M, LOPUSNIAK, M: Experiences and knowhow from Implementation of Experimental Low-energy House in Accordance with Criterions of Sustainable Civil Engineering. In: CESB 10: Central Europe towards Sustainable Building: Prague, Czech Republic 2010. 